\title{
Correction to: Diagnostic utility of a targeted next-generation sequencing gene panel in the clinical suspicion of systemic autoinflammatory diseases: a multi-center study
}

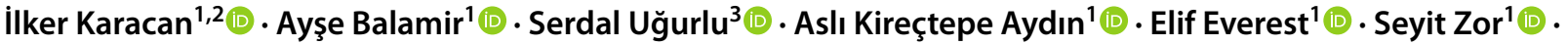

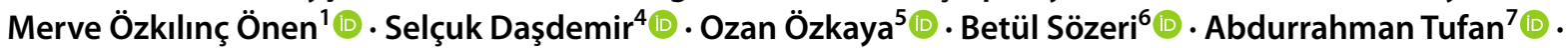 \\ Deniz Gezgin Yıldırım ${ }^{8}$ (1) Selçuk Yüksel ${ }^{9}$ (D) Nuray Aktay Ayaz ${ }^{10}$ (1) $\cdot$ Rukiye Eker Ömeroğlu $^{11}$ (1) Kübra Öztürk $^{12}$ (1)

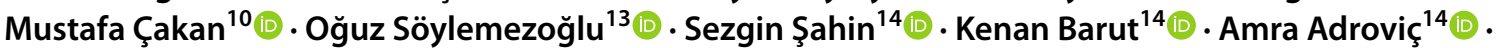 \\ Emire Seyahi ${ }^{3} \cdot$ Huri Özdoğan $^{3}$ (1) $\cdot$ Özgür Kasapçopur ${ }^{14}$ (1) $\cdot$ Eda Tahir Turanlı, ${ }^{11^{1}}$
}

Published online: 18 March 2019

(c) Springer-Verlag GmbH Germany, part of Springer Nature 2019

Correction to: Rheumatology International https://doi.org/10.1007/s00296-019-04252-5

The second affiliation of the corresponding author Eda Tahir Turanlı was incorrectly published as İstanbul Medeniyet University instead of Istanbul Technical University.

In the fourth paragraph of discussion section: the sentence "XXXX et al. have previously reported two families with atypical FMF findings without $M E F V$ gene involvement" was incorrectly published. The correct sentence is "We have previously reported two families with atypical FMF findings without $M E F V$ gene involvement".

The original article can be found online at https://doi.org/10.1007/ s00296-019-04252-5.

Eda Tahir Turanlı

turanlie@itu.edu.tr

1 Department of Molecular Biology-Genetics and Biotechnology, Dr. Orhan Öcalgiray Molecular Biology-Biotechnology and Genetics Research Centre, Graduate School of Science, Engineering and Technology, İstanbul Technical University, Ayazağa Campus, Maslak, 34469 Istanbul, Turkey

2 Department of Molecular Biology and Genetics, Istanbul Medeniyet University, Istanbul, Turkey

3 Division of Rheumatology, Department of Internal Medicine, Cerrahpaşa Medical Faculty, İstanbul University-Cerrahpaşa, Istanbul, Turkey

4 Department of Medical Biology, Faculty of Medicine, Istanbul University, Istanbul, Turkey

5 Department of Pediatric Nephrology, Faculty of Medicine, Istinye University, Istanbul, Turkey

6 Department of Pediatric Rheumatology, Ümraniye Training and Research Hospital, Istanbul, Turkey
In the ethical approval section: the sentence "This study was approved by the Ethics Review Committee of XXXXXXX (approval number and dates: B.30.2.IST.0.30.90.00/19756, 3 July 2012 and 83045809604.01.02, 6 December 2016)" was incorrectly published. The correct sentence is "This study was approved by the Ethics Review Committee of Cerrahpaşa Medical School (approval number and dates: B.30.2.IST.0.30.90.00/19756, 3 July 2012 and 83045809-604.01.02, 6 December 2016)".

Publisher's Note Springer Nature remains neutral with regard to jurisdictional claims in published maps and institutional affiliations.

7 Division of Rheumatology, Department of Internal Medicine, Faculty of Medicine, Gazi University, Ankara, Turkey

8 Department of Pediatric Rheumatology, Faculty of Medicine, Gazi University, Ankara, Turkey

9 Department of Pediatric Rheumatology, Faculty of Medicine, Pamukkale University, Denizli, Turkey

10 Department of Pediatric Rheumatology, Kanuni Sultan Süleyman Training and Research Hospital, Istanbul, Turkey

11 Department of Pediatric Rheumatology, Istanbul Faculty of Medicine, Istanbul University, Istanbul, Turkey

12 Department of Pediatric Rheumatology, Faculty of Medicine, Kocaeli University, Kocaeli, Turkey

13 Department of Pediatric Nephrology, Faculty of Medicine, Gazi University, Ankara, Turkey

14 Department of Pediatric Rheumatology, Cerrahpaşa Medical Faculty, Istanbul University-Cerrahpaşa, Istanbul, Turkey

15 Department of Molecular Biology and Genetics, Istanbul Technical University, Istanbul, Turkey 